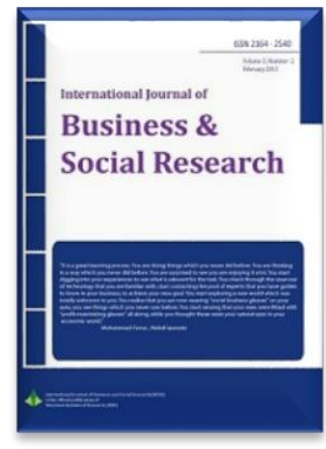

\title{
The Obstacles Facing Young Saudi Men and Women Getting jobs in Small Businesses Sector
}

\author{
Nayef Saleh Al-Ghamri'
}

\begin{abstract}
Small businesses are considered the backbone of the national economy due to their role in creating job opportunities for young men and women who seek private sector employment. However, a series of obstacles face young Saudi male and female citizens in getting jobs in small businesses sector. The present research focuses on studies which discuss the definitions of small businesses and how they are related to the creation of employment opportunities for young men and women, their effect on improving young adults' economic and social levels by boosting their morale and kindling their entrepreneurial spirit. The research also sets out the proposed mechanisms for the removal of obstacles faced by young small business would-be entrepreneurs. Furthermore, it endeavors to develop solutions, based on hypotheses and primary assumptions, which may contribute to a better understanding of the employment issue of Saudi young men and women. Solutions are set within a comprehensive strategy framework based on the integration and encouragement of young people to initiate small businesses, raise their standard of living, reduce the unemployment phenomenon and its consequences and repercussions which can result in domestic discord and moral degenerationwhich may sometimes lead to misanthropy and suicide, as is the case in some societies such as Japan (Al-Saidani, 2010).
\end{abstract}

Keywords: job opportunities, Saudi Arabia, small businesses, unemployment.

Available Online: $26-05-2016$

This is an open access article under Creative Commons Attribution 4.0 License, 2016.

\subsection{INTRODUCTION}

Small businesses are considered as one of the pillars of the Saudi economy due to their significant role in creating job opportunities for many individuals, especially young men and women, despite the widespread inherent preference of some to engage in family-managed businesses or to work in the public sector. In a business sectors' model, small businesses are at the base of the pyramid with considerable size in many underdeveloped countries, especially in the Kingdom of Saudi Arabia (KSA), a country known for its commercial nature and not for its industrial activities. Small businesses are vitally important to the national economy (Saif, 2014) and are seen as the economy's backbone, since they employ the highest percentage of the workforce. They also make essential contributions to the growth of state revenues

\footnotetext{
${ }^{1}$ King Abdulaziz University. Email: nayef.alghamri@gmail.com
} 
from taxes and fees charged on exported goods. In addition, they provide increased purchasing power for many individuals. Hence, many research studies (Baybars, 2013) as well as expert in the field of economy perceive the importance of providing technical and financial assistance to small businesses. Government agencies also play a supporting role by providing training for young people, contributing in resolving their administrative and accounting problems, developing their skills, and offering long-term bank loans with low interest rates. Some studies have recommended the creation of a formal link between the Ministries of Planning, Finance, Labor, and Industry and Trade in order to coordinate and follow up the efforts aiming to support small businesses. It has been recommended that such a body also be tasked with: setting up a national definition of small businesses in terms of standard classification; following up the development of the performance and status of small businesses; demonstrating and testifying as to the role of small businesses in contributing to, and accelerating the pace of economic growth; and their role in job creation and provision of additional income for many lower-income earners. (Al-Asraj, 2010)

\subsection{RESEARCH PROBLEM}

One of the concerns of decision-makers, many societies and even young people themselves is the creation of employment opportunities for young people. Economic and social policies focus on identifying and disclosing all the conditions that hinder job creation for this essential sector in society. KSA has put in lot of efforts and taken corrective actions to improve employability of young people in Saudi private sector businesses through the implementation of an established set of procedures. There remain however, a variety of impediments relating to the employment of young people in the small business sector. The current research study examines and diagnoses the obstacles encountered with a view to enabling identification of the required corrective strategies and actions.

\section{IMPORTANCE OF THE RESEARCH}

The importance of this research is derived from the importance of small businesses and the leading role they play in the creation of employment opportunities for young job seekers. Moreover, young people can start small businesses on their own since they do not require a large amount of capital. Nevertheless, the initial driving business concept and the actual small business start-up are crucial factors in determining the eventual success or otherwise of the business.

\subsection{RESEARCH GOALS AND OBJECTIVES}

This research study mainly aims to identify the obstacles that face young Saudis in seeking employment opportunities in the small businesses sector. It highlights a number of economic and social obstacles which stem from society's views and perceptions of some businesses. These obstacles also involve some businessmen's stereotypical perspectives of Saudi youth, the work environment itself, young people's ambitions, the State's role, and the current lack of employment opportunities.

\subsection{RESEARCH HYPOTHESES}

The Researcher seeks to achieve the objectives of this study by testing the validity of a set of hypotheses as follows:

The first hypothesis: There is a statistically significant relationship between the small business work environment and the obstacles facing young men and women's employment in this sector.

The second hypothesis: There is a direct positive correlation between society's views and perceptions of some businesses and the employment of young men and women in such small businesses.

The third hypothesis: There is a direct relationship between young men and women's ambitions and aspirations and the types of jobs available in small businesses.

The fourth hypothesis: There is a direct statistically significant positive correlation between businessmen's perspectives of young people and their appointment in the private sector.

The fifth Hypothesis: There is an evident direct positive relationship between the role of the state and the entrance of young men and women into employment in small businesses. 
The sixth hypothesis: There are favorable and unfavorable factors which may either lead to young men and women being attracted by the idea of entering into employment in small businesses, or to them viewing such employment opportunities unfavorably and hence to their being reluctant to enter that employment sector.

The seventh hypothesis: There is a direct statistically significant correlation between the lack of job opportunities and social problems such as domestic discord and moral deterioration.

\subsection{THEORETICAL FRAMEWORK}

There is no general consensus on the definition of 'small business'. It varies from one country to another and from one commercial sector to another. A small business is defined as an independently owned and operated enterprise accounting for a limited market share. Some characteristics such as the number of employees, business capital, technology used and sales volume can impact the definition of a small business. It is also defined as a business managed by a single individual, who remains personally liable to the full extent, and employs between 10 to 50 employees. Collectively, the GCC countries have established the invested capital standard to distinguish between industries, whereas small industries are defined as enterprises whose average invested capital is less than two million dollars. (Salibi, 2011). Since unemployment has become a widespread phenomenon in the Arab nations, the majority of Arab countries, including KSA, have sought to address this issue by encouraging young people to engage in small businesses. Measures have been taken to develop appropriate systems and policies, as in KSA, and to offer financial facilities and reduced interest rates (Dawabbah, 2006). Many officials have started to approach the subject by stressing the importance of small businesses as being the best means to employ the young workforce. (Mefleh, 2016). It is obvious that small businesses of young people provide the right path to self-employment. They also contribute in kindling the spirit of creativity and innovation, and help to break free from the chains of a routine employment. (Lazem 2014). Economic boom can only occur via development of human resources and the encouragement of young people to proactively engage in the small business sector. All incentives and inducements should be provided to small businesses such as financial, bank funding, technical and consultation support. However, this can only be achievable by means of combined economic, social, political and cultural efforts. It is worth mentioning that small businesses are now inseparable from the dynamic world and are impacted by globalization and World Trade Organization (WTO) rules, where competition is based on high quality and low prices. Small businesses are at the base of the pyramid of any business sector and are deemed as seeds that are transformed into trees, which upon maturity, form larger business entities and operations. (Al-Jundi, 2015). Based on 1996 statistical data, there are a total of 18 million enterprises in the European Union (EU) contributing $66 \%$ of labor force employment. While unemployment of young people is the main concern of both the public and private sectors, there are worries that the phenomenon might become more severe. The following Chart shows unemployment rates among Saudis from 1999 to 2009. The unemployment rate increased from 8.1\% in 1999 to $12 \%$ in 2007. (Riyadh Chamber of Commerce \& Industry (RCCl), 2010).

Chart 1: The unemployment rate in Saudi Arabia during the period from 1990 to 2000

The Unemployment Rate in Saudi Arabia During the Period from 1990 to 2000

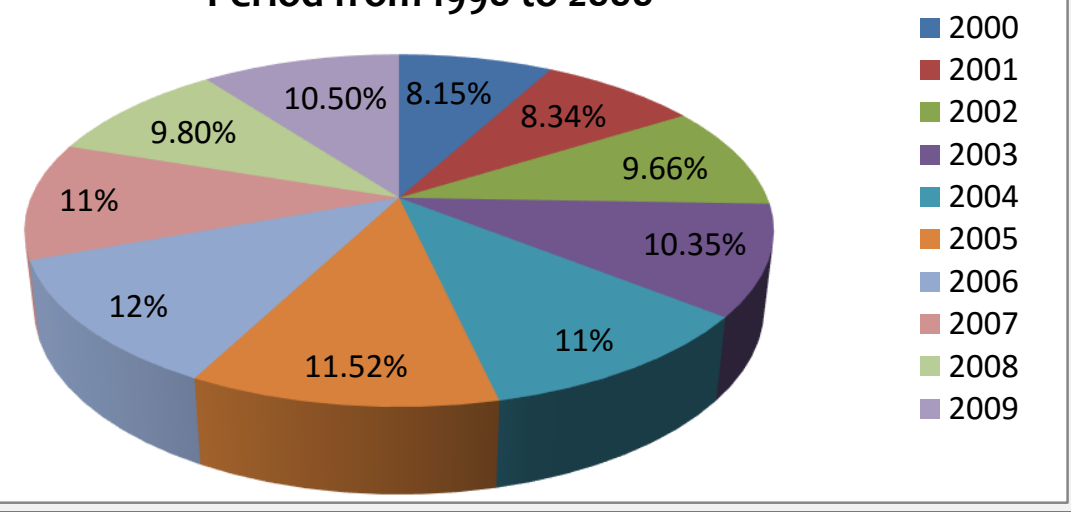


The increase in the unemployment rate is attributable to high birth rates, non-alignment of education and training with labor market needs, insufficiently proactive remedial strategies, and reluctance of jobseekers to engage in the private sector.

\subsection{ADMINISTRATIVE, ECONOMIC AND SOCIAL OBSTACLES}

Administrative and legal obstacles, as well as economic challenges, are identified as the foremost issues facing developing countries. It should be noted that administrative problems are difficult to resolve due to established, and to a certain extent set, administrative performance levels. There is also an urgent need for rapid development of managerial concepts, and the adoption of modern techniques in marketing, finance and production. Legal obstacles include the absence of private and public sector programs to support and protect small businesses. Laws regulating import and export also can negatively impact such businesses. Their growth prospects can also be affected by lack of social security frameworks in these businesses and by government bureaucracy. In addition to the above-mentioned administrative and legal obstacles, there are additional obstacles such as bank financing difficulties, high interest rates, and short loan repayment periods. Due to small businesses' failure risks, commercial banks may refrain from offering credit/financing needed for these businesses - particularly because they are not able to demonstrate sufficient levels of research and development (R\&D). One of the significant characteristics of small businesses is their tendency to follow traditional technology methods. Numerous economic challenges also exist, including inflation which affects the rate of increase in prices of raw materials and labor costs - inevitably leading to higher operating costs. Shortage of well-trained workers with vocational and technical skills and lack of targeted training programs are also other main problems encountered by small businesses and which, by their nature are problematic to solve. The reluctance of young people to seek employment in small businesses primarily emerges from the character of the young people themselves. For a variety of reasons, they are seen as lacking in entrepreneurial and innovative spirit. Some small business jobs are widely, unfairly and unfortunately socially devalued and looked upon as being somehow socially unacceptable to job seekers. There is a widespread and pervasive preference for the job security that is perceived as part and parcel of public sector/government employment. This is accompanied by reluctance and even unwillingness to accept the risks inherent in new commercial business start-ups. The combination of these factors and perceptions has served to shape a negative work environment which affects the success and sustainability of small businesses. (Arab Labor Organization, 2009).

\subsection{PREVIOUS STUDIES}

The United Nations Conference on Trade and Development (UNCTAD) held in Doha in 2012 discussed a Memorandum on promoting youth entrepreneurship. Discussions were held for the purpose of facilitating the participation of young people in improving the productive capacity of developing countries, as well as to enhance their ability to adapt to future challenges.

Studies focused on the following three themes:

First: $\quad$ Update data on youth unemployment.

Second: Highlight the importance of enhancing an enabling environment to promote entrepreneurship among young people.

Third: $\quad$ The challenges faced by young entrepreneurs.

\section{(United Nations Conference on Trade and Development (UNCTAD), 2014)}

A study prepared by Barclays Bank (Schoof, 2006) refers to the economic and cultural obstacles facing small businesses. They are listed according to their order of importance: small business owners are not seriously regarded by the wider private/business sector of which they are a part; they face age discrimination either by customers, other enterprises or governmental institutions; they lack the support of family and friends. Another study (Ernst \& Young, 2013) highlighted obstacles to the growth of small businesses including financial, educational, regulatory and administrative barriers. The majority of the young entrepreneurs surveyed were in need of funding (73\%) or tax reduction. In a study conducted in 
Palestine (Miqdad and Bahloul, 2014) the results manifested the weak role of universities in providing employment opportunities for graduates and demonstrated that they do not qualify them for future employment. Graduates state that the curricula they study do not match or respond to labor market demands, and are only theoretical rather than practical in nature. These results possibly reflect the extent of frustration of graduates due to lack of employment opportunities.

\subsection{RESEARCH METHODOLOGY}

\subsection{THE ADOPTED RESEARCH APPROACH}

A Descriptive-Analytic Approach has been mainly adopted for the purposes of this study. The DescriptiveAnalytic Approach is defined as an analysis method which depends on sufficient and accurate information about a phenomenon or a specific issue throughout a known period or periods of time. It has been used to reach practical results that are objectively interpreted in consistency with the actual data of the phenomenon. (Obeidat, Adas and Abdulhaq, 1982)

\subsection{THE POPULATION OF THE STUDY}

The population from which the respondents were selected includes small business owners in Jeddah city. Due to the city's large population and the logistical research hurdle of covering such numbers, the researcher has selected to rely on a simple random sample of 100 individuals $(n=100)$ of small business owners to represent the city's population for this study. A survey was distributed to the potential participants manually. After the completion of the data collection process, the researcher was able to obtain complete answers to the questionnaire from 99 respondents, which were then analyzed and examined.

\subsection{RESEARCH TOOLS}

To collect and extract all the required information from the selected sample, the researcher relied on a survey consisting of a series of 34 questions. The main variables, covering the study hypotheses, were built into the questionnaire. The survey also consisted of variables related to the characteristics of the target sample such as gender, years of previous experience, age and qualifications.

\subsection{VALIDITY AND RELIABILITY INDICATORS OF THE QUESTIONNAIRE}

First: Internal consistency as a measure for test validity: The researcher verified the validity of the assessment method in the exploratory phase by selecting a random sample of 15 employees working in Jeddah small businesses. This was carried out in order to assess the consistency of the gathered data across the questionnaire items. Bivariate correlation was carried out on each item score in order to determine its internal consistency with the total scores of the category to which it belongs. The results revealed that the majority of the questionnaire items are correlated with the total score of the category to which they belong. Moreover, all the bivariate correlation coefficient values are statistically significant at the 0.01 level. The correlation coefficient values ranged from 0.40 to 0.81 . Therefore, we are able to conclude that the majority of the assessment method items have a high degree of validity, a case which indicates that they have achieved their desired measurement objectives. The researcher has also verified the assessment method validity by calculating the correlation between each category of the assessment method with the total score of the method as shown in Table (1).

It is clear from the results of Table (2) that all assessment method categories are significantly correlated with assessment method total score. This shows that all the categories have a high degree of validity with the total score of the survey used to collect primary data. The values for the correlation coefficient ranged from 0.37 to 0.76 . Therefore, all the categories achieve the desired measurement objectives. 
Table 1: The Correlation Coefficient between the Score of Each Category with the Total Score of the Method (Survey)

\begin{tabular}{lrr} 
Categories & $\begin{array}{r}\text { No. of } \\
\text { Items }\end{array}$ & $\begin{array}{r}\text { Correlation } \\
\text { Coefficient }\end{array}$ \\
\hline First Category: The small businesses work environment & 4 & $* * 0.54$ \\
Second category: Society's views and perceptions of some businesses & 5 & $* * 0.66$ \\
Third category: Young men and women's ambitions and the types of & 3 & $* * 0.50$ \\
available employment in small businesses & 8 & $* * 0.76$ \\
Fourth category: Businessmen's perspectives of Saudi youth & 6 & $* * 0.64$ \\
Fifth category: The State's role & 5 & $* * 0.57$ \\
Sixth category: Attraction and reluctance factors for young people & 3 & $* * 0.37$ \\
Seventh category: Social Problems & & \\
$* *$ Correlation is significant at the 0.01 level. & &
\end{tabular}

\subsection{RELIABILITY OF THE ASSESSMENT METHOD}

The reliability of the assessment method by the split-half reliability methodology:

The researcher has explored the reliability of the assessment method by the split-half reliability methodology through measuring the coefficient of overall score of even items and the overall score of odd items using Pearson's Correlation Coefficient, $r$, corrected by the Spearman-Brown formula to get a better estimate of the full test's reliability. It is clear that the value of Pearson's Correlation Coefficient, $r$, between odd and even questions is 0.69 , while Spearman-Brown Coefficient is 0.65 . Therefore, we are able conclude that the assessment method demonstrates a high level of reliability, a case which reassures the researcher that the assessment method is well-designed, as shown in Table (2).

Table 2: Reliability of the Assessment Method Using the Split-half Reliability Methodology Coefficient Correlation Coefficient

Pearson's Correlation Coefficient $* * 0.69$

Spearman-Brown Coefficient $* * 0.65$

** Correlation is significant at the 0.01 level

The overall reliability coefficient of the survey was measured by using Cronbach's coefficient Alpha ( $a$ ). The reliability coefficient value indicates that the survey method has achieved a high degree of reliability of 0.81 , a case which, in its turn, provides sufficient reassurance to the researcher concerning the quality of the categories and their items' design.

\subsection{STATISTICAL METHODS USED}

Descriptive statistics to perform a statistical analysis of the study data aiming at the achievement of underlying objectives and verification of the research hypotheses, was performed. The descriptive methodology has been used to summarize data from the sample using indexes, such as replicates and percentages, to describe the sample according to demographic characteristics. Other indexes, such as the mean and standard deviation have been used to measure the response rate of the target sample of small business employees for the research categories' items. Pearson's Correlation Coefficient, $r$, to measure the validity of the assessment method was also utilized for this research. The coefficient of Pearson's Correlation Coefficient, r, Spearman-Brown Coefficient and Cronbach's Alpha ( $\alpha$ ) were used to measure the assessment method's reliability and internal consistency. In addition, the researcher used some inferential statistical methods to test for the significance between medians of the respondents' views in the sample regarding the research categories based on demographic variables of the sample (gender, years of experience, age, and qualifications). The applied inferential statistical tests included the "One-Way analysis of variance" (one-way ANOVA) to test the significance of differences between means based on different variables of the study (years of previous experience, age, and qualifications). The Ttest was also used for testing the differences between means based on the gender variable. 


\subsection{DATA ANALYSIS AND DISCUSSION}

The aim of analyzing, interpreting and discussing the gathered data is primarily to identify the obstacles faced by young Saudis in finding employment opportunities in the small business sector. In order to do this, the most prominent obstacles/impediments were highlighted in accordance with the respondents' views in the studied sample, all of whom are engaged in the small business sector. This was done with the aim of identifying solutions to perceived issues and raising awareness levels of the young people concerned. The researcher used 'The IBM Statistical Package for the Social Sciences' (SPSS) computer program, version 20.0, to analyze the study's data. The collected data was entered into the software, after being encoded and classified.

\subsection{FIRST: ANALYSIS OF THE DEMOGRAPHIC CHARACTERISTICS OF THE SAMPLE}

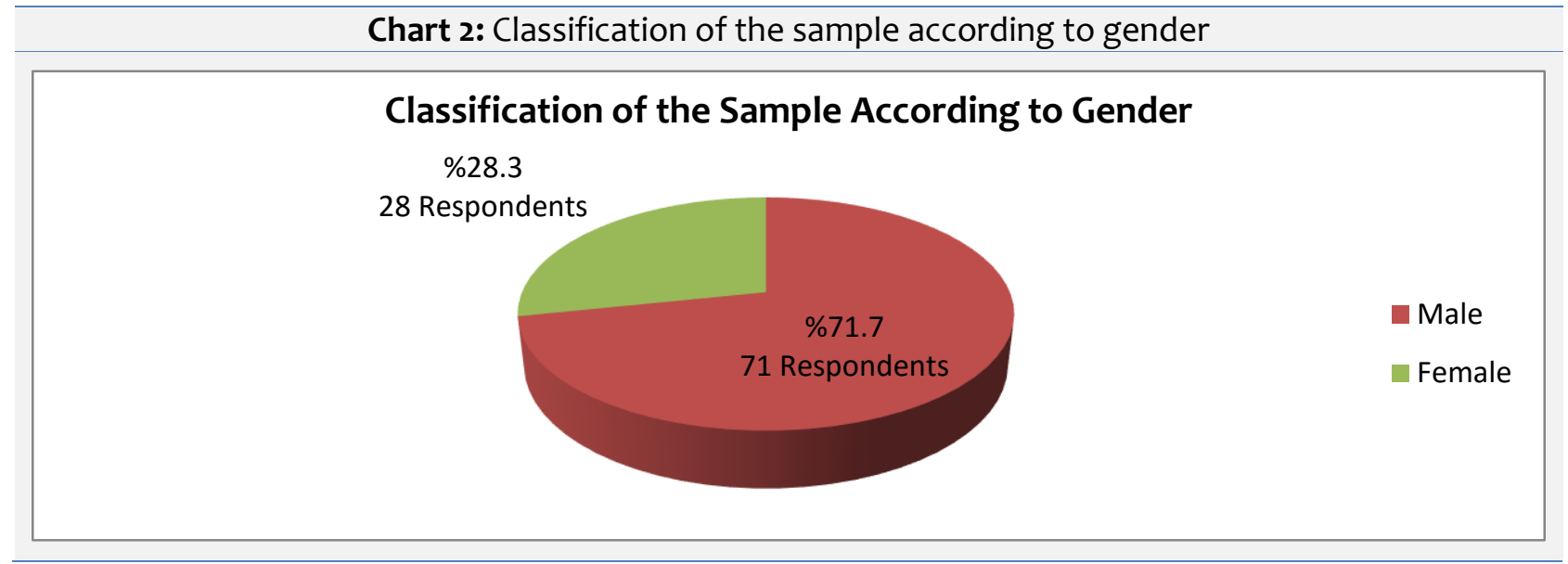

Indicators in the above chart show the classification of the sample of employees, engaged in the small business sector in Jeddah city, according to gender. It is clear that the representation of male participants reached $71.7 \%$ compared to $28.3 \%$ for females. Therefore, it is clear that the majority of the sample is male since the rate of females engaged in small businesses is still relatively low, in spite of the efforts made by the Ministry of Labor in the Kingdom to encourage females' employment.

Chart 3: Classification of the sample according to years of previous experience

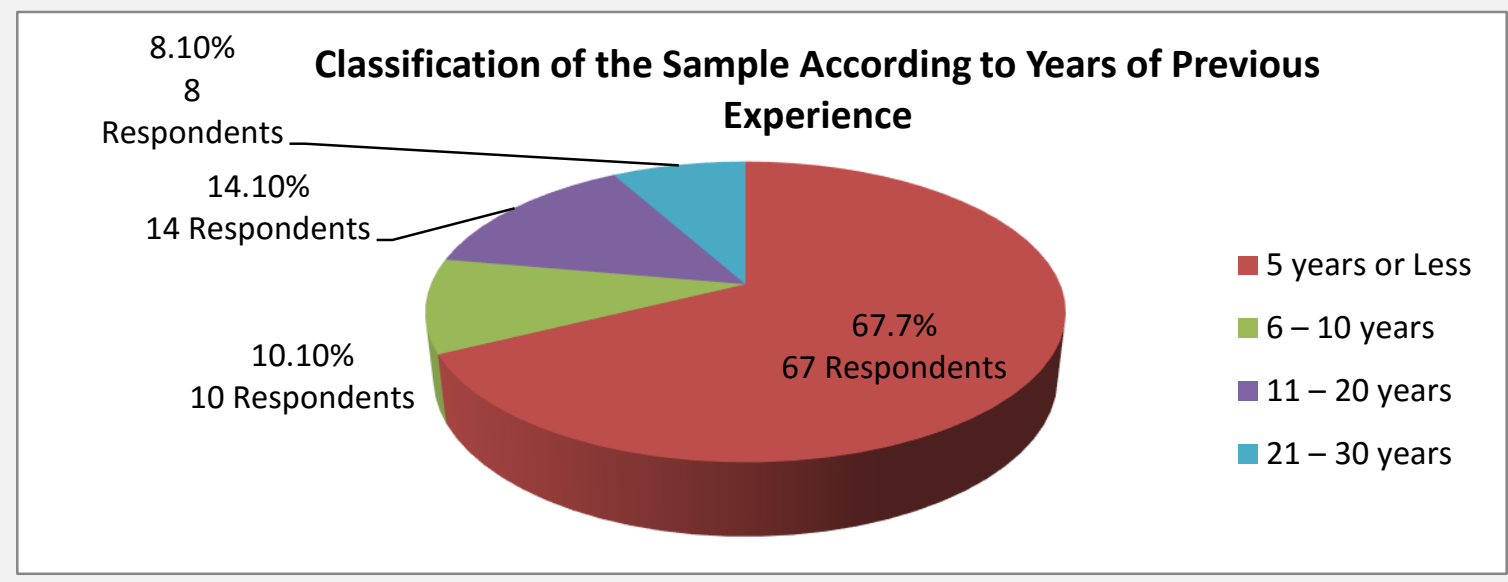

It is clear from the indicators of the above chart that the majority of the respondents in the sample of small business employees participating in this study have five years or less of experience, $10.1 \%$ have a range of between 6-10 years of experience, $14.1 \%$ have a range of between 11-20 years of experience, while only $8.1 \%$ have a range of between 21-30 years of experience. Accordingly, we conclude that the majority of respondents participating in this study have five years or less of experience. The high rate of this 
category is due to the latest measures taken, which have focused on achieving target Saudi rates for all enterprises operating within the Saudi economy.

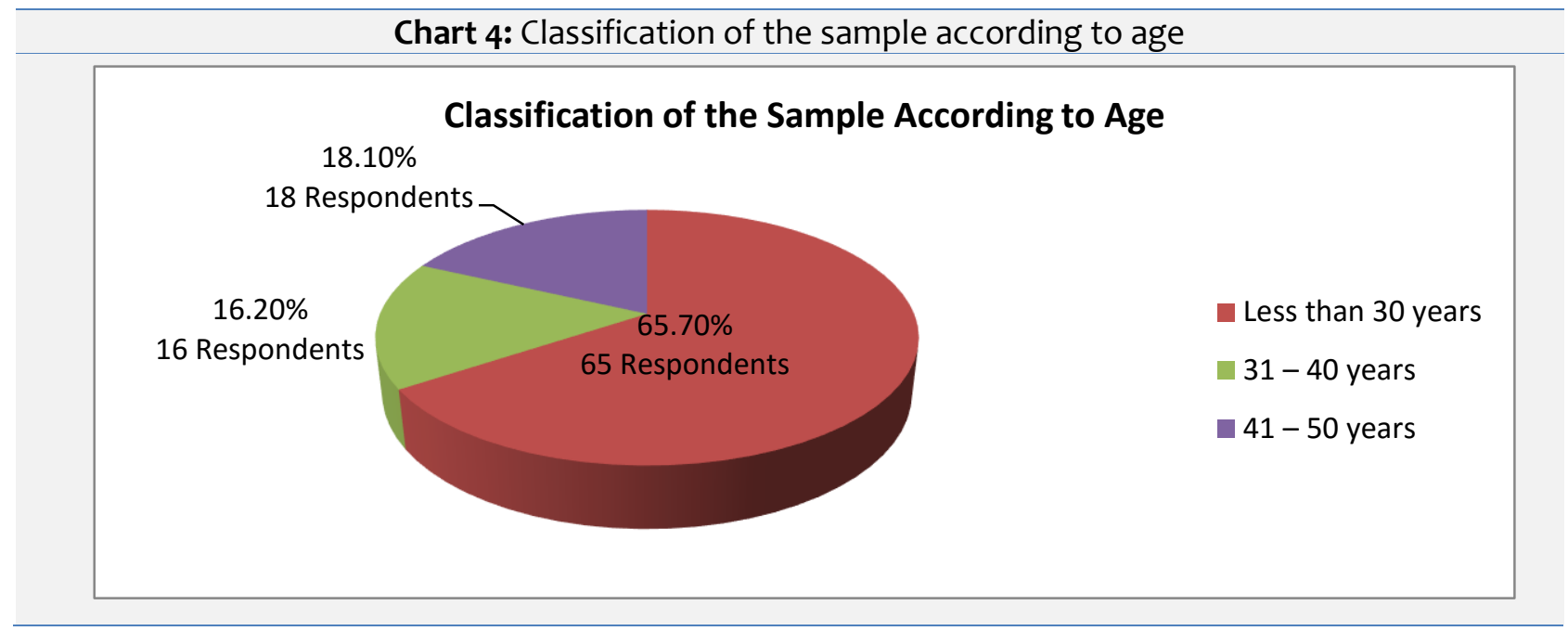

It is clear from the indicators of the above chart that the majority of the sample respondents participating in this study are less than 30 years old, $16.2 \%$ are $31-40$ years old, while only $18.1 \%$ are $41-50$ years old. Accordingly, we conclude from the above indicators that the majority of the small business employees participating in this study are young people, who form this study's core subject. They are best able and suited to evaluate the obstacles facing young Saudis in employment in small businesses based upon their practical experience in these types of businesses.

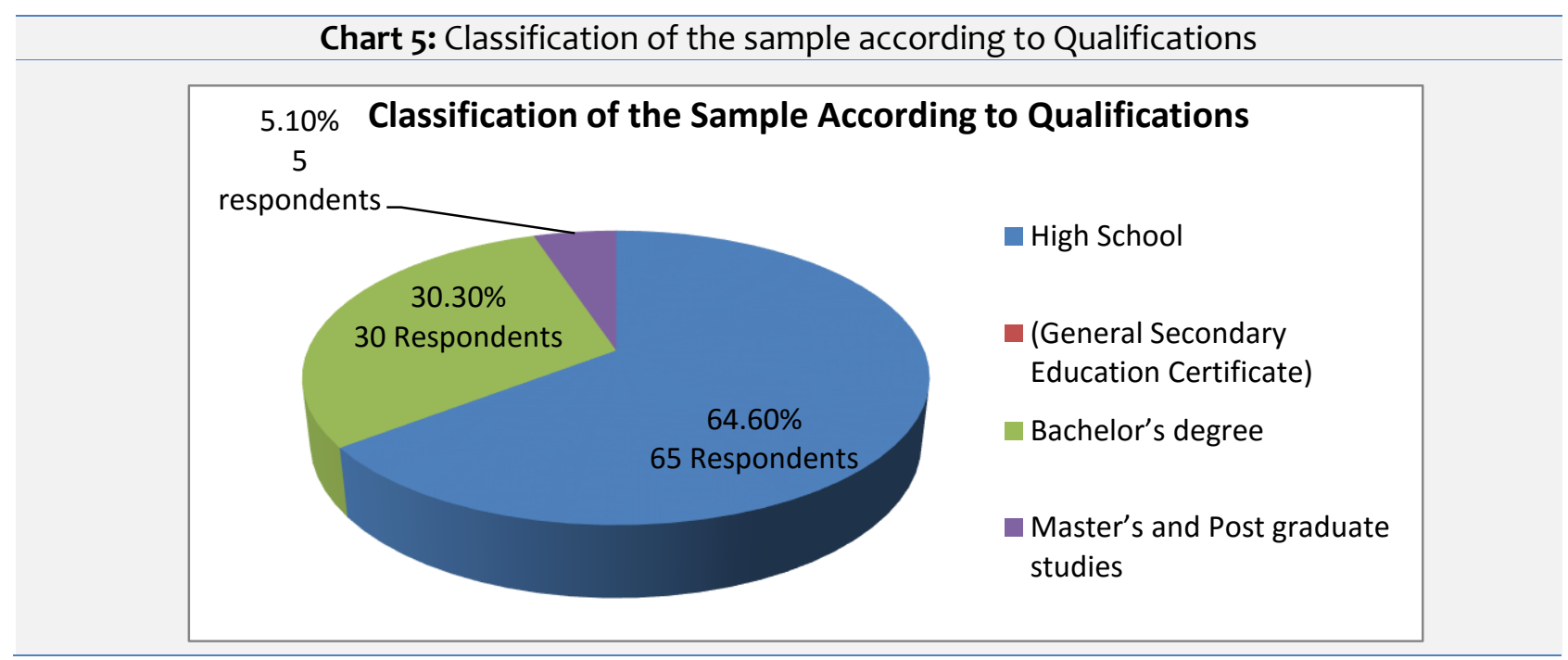

Indicators in the above chart show the classification of the sample according to qualifications. It is clear that the majority of the respondents participating in this study hold a high school certificate since they represent $64.6 \%$ of the total sample size, $30.3 \%$ hold a Bachelor's degree, while $5.1 \%$ hold a Master's degree or a Post graduate certificate. Accordingly, we conclude from the previous indicators that the majority of the small business employees participating in this study hold a high school certificate. This is possibly due to the capacity of these businesses to employ this category owing to the low costs involved in employing this specific category.

\subsection{SECOND: RESULTS OF TESTING THE HYPOTHESES OF THE STUDY}

In this part of the analysis of the study data, the researcher deals with the results of the study hypotheses, which aim to identify the main obstacles hindering the effective and productive employment of young Saudi men and women in small businesses in KSA. 
By such identification, the researcher also aims at identifying corrective remedial actions and strategies that can contribute to the expansion and enhancement of the employment prospects of young Saudis in these businesses.

\subsection{THE RESULTS OF TESTING THE FIRST HYPOTHESIS:}

'There is a statistically significant relationship between the small business work environment and the obstacles facing young men and women's employment in this sector.'

Table 3: Display of the Arithmetic Mean and Standard Deviation of the sample of small business employees' responses to the questionnaire on work environment

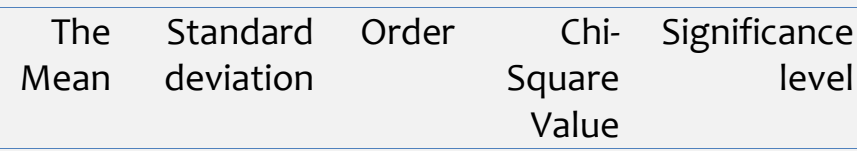

1 Non-application of civil service standards such as retirement and promotion employment laws and job stability.

$\begin{array}{lllll}4.12 & 0.86 & 1 & * * 85.6 & \text { Significant }\end{array}$

2 Size of the small businesses sector and their inability to offer salary payments to young Saudis equivalent to salary and compensation schemes of public sector/government employees.

$\begin{array}{lllll}4.03 & 0.97 & 2 & * * 73.78 & \text { Significant }\end{array}$

3 Inadequate work environment in small business factories leads to the unwillingness of young Saudis to seek employment in these businesses.

4 Pressure and quantity of work in small businesses are higher than in the public lgovernment sector.

The Weighted Average

$\begin{array}{lllll}3.60 & 0.91 & 4 & * * 57.31 & \text { Significant } \\ 3.84 & 1.04 & 3 & * * 38.93 & \text { Significant } \\ 3.90 & 0.55 & & & \\ & & & & \end{array}$

**The Chi-Square value is statistically significant at the level $(\alpha)$ of 0.01

The indicators in Table (3) show the views of the sample of small business employees, participating in the current study, concerning the existence of a statistical significance between the work environment of small businesses and the obstacles facing young men and women engaged in these businesses. The table shows the Weighted Average of 3.90 for the responses of the survey sample and a standard deviation of 0.55. Therefore, we conclude that the majority of the respondents in the sample hold the view that the work environment has a great impact on Saudi young men and women's employment in the small business sector. The results of Table (3) shows that the absence of civil service standards such as retirement and promotion systems, employment laws and job stability are considered as major obstacles facing young men and women in employment in small businesses. This result is supported by the arithmetic mean of 4.12 and a standard deviation of 0.86 . The results of Table (3) also show that the size of the small businesses sector and their inability to offer salary payments to young Saudis equivalent to the salary and compensation schemes of public sector/government employees is considered the second ranked obstacle related to the work environment facing young men and women's employment in these businesses. This result is supported by the arithmetic mean of 4.03 and a standard deviation of 0.97 . The results of Table (3) also reveal that pressure and work quantity in small businesses are higher than in the public sector. It is therefore regarded as one of the obstacles of the work environment facing young men and women's employment in the small business sector and has ranked third. This result is supported by the arithmetic mean of 3.84 and a standard deviation of 1.04. The results of Table (3) also show that the inadequate work environment in small business factories leads to the reluctance and unwillingness of young Saudis to seek employment in these businesses. This result is supported by the arithmetic mean of 3.60 and a standard deviation of 0.91 . This element ranked the fourth and lowest of the obstacles 
related to the work environment. The results of Table (3) also show that all Chi-Square values are statistically significant at the level $(\alpha)$ of 0.01 . This supports the proposition that work environment has a high influence over young Saudis' employment in the small business sector. It also means that the work environment contributes to the reluctance of young Saudis to seek or take up employment in the small business sector. Therefore, we conclude from the previous indicators that the work environment plays a key role in the reluctance of young Saudis to seek and enter into employment in the small business sector. It is hence considered to be one of the obstacles facing young people's employment in small businesses. The results show that the most important element of the work environment facing young people is the non-application and implementation of civil service standards such as retirement and promotion systems, employment laws and job stability. The second ranked obstacle is the size of the small businesses sector and their inability to offer salary payments to young Saudis equivalent to the salary and compensation schemes of public/government sector employees - which leads them to prefer to wait and seek employment opportunities in the public/government sector or in enterprises in other sectors with job security and stability.

\subsection{THE RESULTS OF TESTING THE SECOND HYPOTHESIS}

'There is a direct correlation between society's views and perceptions of some businesses and the employment of young men and women in such small businesses.'

Table 4: Display of the Arithmetic Mean and Standard Deviation of the sample of small business employees' responses to the questionnaire on the society's views and perceptions of some businesses

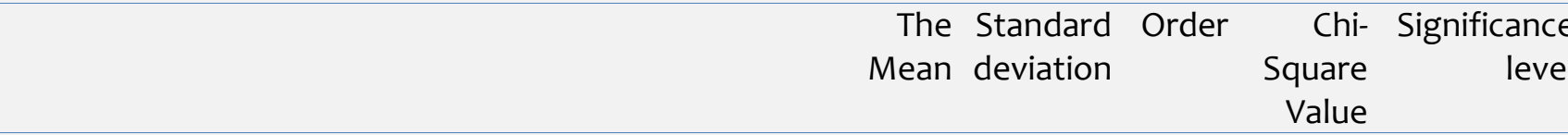

1 One of the reasons for loss of job opportunities is young people's objection to work outside city borders.

$3.94 \quad 1.06 \quad 2^{* * 35.27}$ Significant

2 A lot of young people reject to work in car maintenance jobs, although they provide a high income, in fear to bring shame or dishonor upon the

$3.65 \quad 1.22 \quad 4^{* * 23.78}$ Significant
family.

3 The society's views and perceptions of low-skilled jobs, in general, are of low value and such jobs are considered shameful and demeaning.

$3.64 \quad 1.03 \quad 5^{* * 36.91}$ Significant

4 A lot of young women prefer a teaching career, even if it is located far from their place of residence, and are unwilling to work in small businesses where both genders mingle together because of fear of male harassment.

5 One of the reasons for loss of job opportunities is the youth's dependency on parents in providing for a lot of requirements, even after graduation from college, due to lack of adequate preparation for adult responsibly and self-reliance.

The Weighted Average

$4.04 \quad 0.99 \quad 1^{* * 54.08}$ Significant

$3.86 \quad 1.03 \quad 3^{* *} 42.77 \quad$ Significant

**The Chi-Square value is statistically significant at the level $(\alpha)$ of 0.01

The indicators in Table (4) show the views of the sample of small business employees, participating in the current study, concerning the existence of statistical significance between society's views and perceptions of some businesses and the employment of young Saudis in small businesses. The table shows the Weighted Average of 3.82 for the responses of the survey sample and a standard deviation of 
0.60. Therefore, we conclude that the majority of the respondents in the sample hold the view that society's views and perceptions of some businesses have a great impact on young Saudis' employment in the small business sector. The results of Table (4) show that the most dominant element in society's views and perceptions, with the strongest influence on young Saudis' employment in small businesses, is that a lot of young women prefer a teaching career, even if located far from their place of residence, and are unwilling to work in small businesses where both genders mingle because of fear of male harassment. This result is supported by the arithmetic mean of 4.04 and a standard deviation of 0.99 . Accordingly, the preference of a teaching career in locations far away from residence and family is a difficult choice but is considered a better choice than one that involves mingling with the other gender or becoming subjected to harassment by young men. This reflects the societal views of female employment, which represent the widespread unwillingness of women to mingle with men in the workplace. The results of Table (4) show that the second element related to the society's views and perceptions of some businesses and the employment of young Saudis in small businesses is that one of the reasons for loss of job opportunities is young people's objection to work outside city limits. This result is supported by the arithmetic mean of 3.94 and a standard deviation of 1.06. Therefore, a large section of young people in the society reject a job outside the city limits, which leads to increased unemployment rates among young people. Accordingly, there is a high necessity to solve these kinds of problems by improving work conditions outside large cities. Solutions may also include incentives such as a 'nonresidence allowance', or raising the accommodation allowance to attract and encourage new segments of young people to work in rural areas away from their urban residences. The results of Table (4) indicate that the third element related to society's views and perceptions of some businesses is represented in young Saudis' dependency on parents for a lot of requirements, even after graduation from college, due to lack of adequate preparation for adult responsibly and self-reliance. This is considered as one of the causes for loss of job opportunities among young people in small businesses. This result is supported by the arithmetic mean of 3.86 and a standard deviation of 1.03. Therefore, we conclude that one of the causes of loss of jobs among young people is dependency on parents to provide for a lot of daily requirements. A father is traditionally responsible for raising his children, bearing the costs of their education, in addition to financially supporting them even after completion of their education. The indicators in the Table show that the fourth element related to the society's views and perceptions of some businesses is represented in the rejection by a lot of young people of work in car maintenance jobs, although they provide a high income, for fear of bringing shame or dishonor upon the family. This result is supported by the arithmetic mean of 3.65 and a standard deviation of 1.22. Therefore, we conclude that the rejection of young people of work in car maintenance jobs is one of the reasons for loss of job opportunities even though the majority of them realize that it is a legitimate and honest livelihood which provides a higher income to an individual than other jobs. The results also show that the fifth and final element which leads to the loss of employment opportunities for young people in the small business sector is that the society's views and perceptions of low-skilled jobs, in general, is that they are somehow of low esteem/ prestige and that such jobs are socially demeaning. This result is supported by the arithmetic mean of 3.64 and a standard deviation of 1.03. Therefore, it is of great importance to change societal views and perceptions towards low-skilled jobs. This goal can be achieved through media channels and linking between universities and society by raising awareness of the importance of young people to engage in low-skilled jobs, especially for those who discontinue their education during the three general education phases. The results of Table (4) also show that all Chi-Square values are statistically significant at the level (alpha) of 0.01. This supports the existence of a relationship between society's views and perceptions of some businesses, especially low-skilled jobs, and the employment of young men and women in the small business sector. Therefore, we conclude that the society's views and perceptions of some businesses and low-skilled jobs have a high impact and discourage young people's employment in small businesses or the start-up of their own small private business - which have been proven to provide a higher income than other jobs.

\subsection{THE RESULTS OF TESTING THE THIRD HYPOTHESIS:}

'There is a relationship between young men and women's ambitions and aspirations and the types of jobs available in small businesses.' 
Table 5: Display of the Arithmetic Mean and Standard Deviation of the sample's responses to the questionnaire on young men and women's ambitions and the types of available jobs

\begin{tabular}{|c|c|c|c|c|c|c|}
\hline & & $\begin{array}{l}\text { The } \\
\text { Mean }\end{array}$ & $\begin{array}{l}\text { Standard } \\
\text { deviation }\end{array}$ & Order & $\begin{array}{l}\text { Chi- } \\
\text { Square } \\
\text { Value }\end{array}$ & $\begin{array}{r}\text { Significance } \\
\text { level }\end{array}$ \\
\hline & $\begin{array}{l}\text { Some jobs are considered undesirable or } \\
\text { unpleasant by young Saudis such as working in } \\
\text { fast food restaurants and small industrial } \\
\text { workshops. }\end{array}$ & 3.55 & 1.21 & 2 & $* * 18.42$ & Significant \\
\hline 2 & $\begin{array}{l}\text { Many young Saudis refuse to work in seasonal } \\
\text { jobs during the Haj season, or work as pilgrim } \\
\text { guides or in tourism. }\end{array}$ & 2.14 & 1.15 & 3 & $* * 42.06$ & Significant \\
\hline 3 & $\begin{array}{l}\text { Some low-skilled jobs such as plumbing, } \\
\text { electrical wiring and construction jobs do not } \\
\text { align with the aspirations of young people by any } \\
\text { means. }\end{array}$ & 3.95 & 1.07 & 1 & $* * 46.81$ & Significant \\
\hline & Weighted Average & 3.21 & 0.86 & & & \\
\hline
\end{tabular}

The indicators in Table (5) show the views of the sample of small business employees, participating in the current study, concerning the existence of statistical significance between young Saudis' ambitions and the types of available jobs in small businesses. The table shows the Weighted Average of 3.21 for the responses of the survey sample and a standard deviation of 0.86 . Therefore, we generally conclude that there is a difference in the sample's views about the existence of statistical significance between young Saudis' ambitions and the types of available jobs in small businesses. This means that there are some views which agree and others which do not agree that young people's strong ambitions do not align with the available job opportunities. The results of Table (5) show that the most dominant element related to the young people's ambitions that limits the utilization of available job opportunities in the small business sector is represented in some low-skilled jobs such as plumbing, electrical wiring and construction jobs that do not correspond at all with the young people's aspirations. This result is supported by the arithmetic mean of 3.95 and a standard deviation of 1.07. The element in the second rank is that there are some jobs that are considered as being undesirable or unpleasant by young Saudis, such as working in fast food restaurants and small industrial workshops. The results of Table (5) also show that all Chi-Square values are statistically significant at the level $(\alpha)$ of 0.01 . This indicates the existence of a relationship between young people's strong ambitions and the non-utilization of job opportunities in the small business sector. Therefore, this result supports the acceptance of the study's third hypothesis.

\subsection{THE RESULTS OF TESTING THE FOURTH HYPOTHESIS:}

'There is a direct statistically significant correlation between businessmen's perspectives of young people and their appointment in the private sector.'

Table 6: Display of the Arithmetic Mean and Standard Deviation of the sample of small business employees' responses to the questionnaire on businessmen's perspectives of young people and the appointment of young Saudis in the private sector 


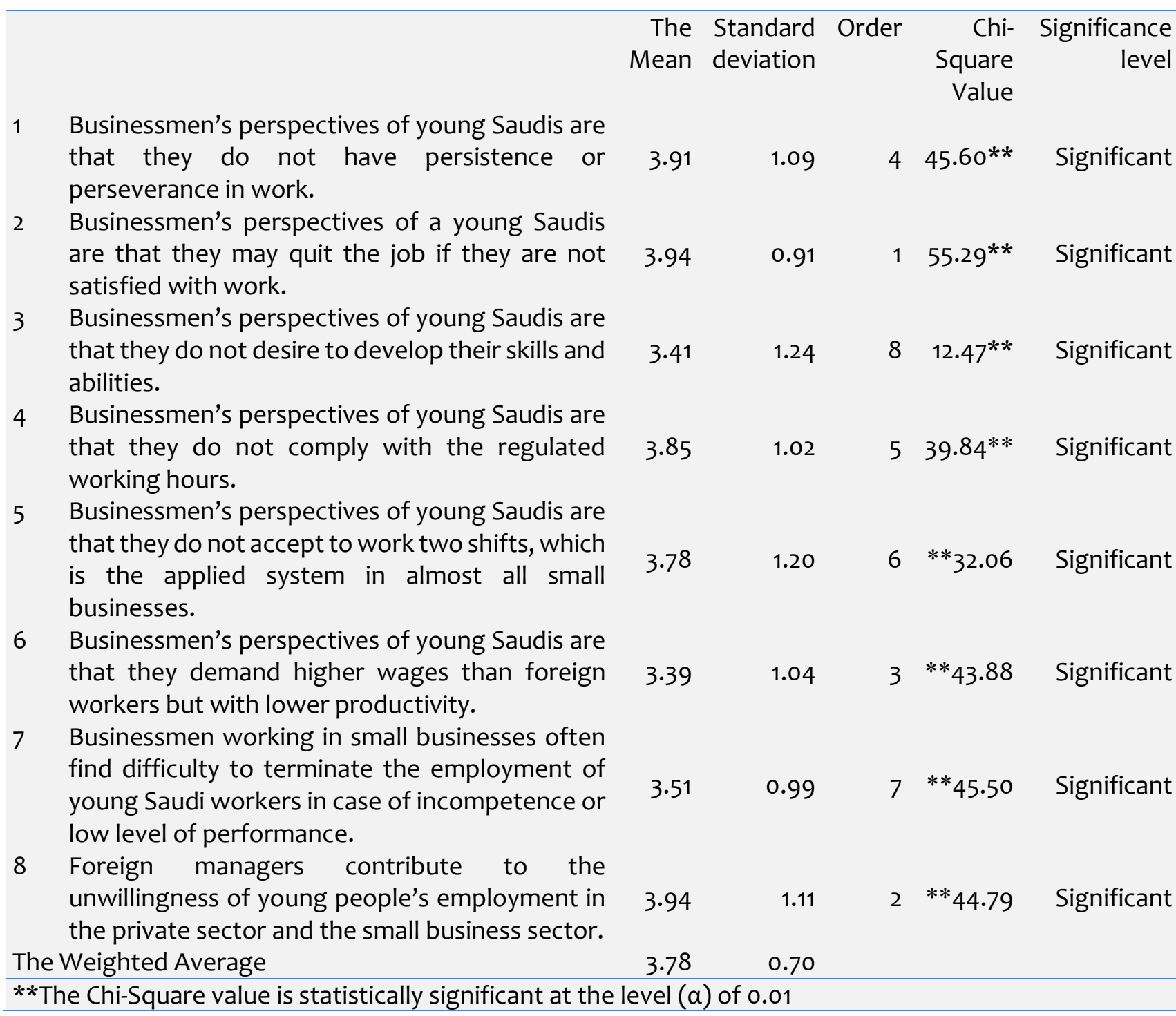

The indicators in Table (6) show the views of the sample of small business employees, participating in the current study, concerning the existence of statistical significance between businessmen's perspectives of young people and their appointment and employment in the private sector. The table shows the Weighted Average of 3.78 for the responses of the survey sample and a standard deviation of 0.70. Therefore, we conclude that the majority of the respondents in the sample agree to a great extent that businessmen's perspectives of young Saudis have contributed to their non-appointment and employment in the small business sector and private enterprises. The results of Table (6) show that the most dominant element in businessmen's perspectives of young people which have strongly influenced the non-appointment of young Saudi people in small businesses, is represented in the statement that businessmen's perspectives of young Saudis are that they may quit if they are not satisfied with the work. This result is supported by the arithmetic mean of 3.94 and a standard deviation of 0.91. The results of Table (6) showed that the second element related to businessmen's perspectives of young Saudis as per the views of the respondents in the sample, is represented in the statement that foreign managers contribute to the unwillingness and perhaps inability of young Saudis to seek and gain employment in the private sector and the small business sector. This result is supported by the arithmetic mean of 3.94 and a standard deviation of 1.11. The results of Table (6) show that the third element related to businessmen's perspectives of young Saudis that contributes to their non-appointment and employment in the small business sector and private enterprises, is represented in the statement that young Saudis demand higher wages than foreign workers but produce less. This result is supported by the arithmetic mean of 3.93 and a standard deviation of 1.04. The results of Table (6) also show that other elements related to businessmen's perspectives of young Saudis, according to their order of importance, which contribute to the non-appointment and lack of employment of young Saudis in the small business sector 
are represented as follows: Young Saudis do not have persistence or perseverance in work; Young Saudis do not accept to work two shifts, which is the applied system in almost all small businesses; It is a difficult to terminate the employment of a young Saudi worker in case of incompetence or low level performance; Moreover, young Saudis do not desire to develop their skills and abilities. These results are supported by the Mean (3.9, 3.85, 3.78, 3.51 and 3.41) consecutively. Therefore, we conclude from the previous indicators that businessmen's perspectives of young Saudis have negatively impacted the appointment of young people in available jobs in the small business sector. This has entailed the foreign workers' acquisition of a greater share of jobs in the private sector, particularly in the small business sector, which represents a high percentage of the volume of business in KSA.

\subsection{THE RESULTS OF TESTING THE FIFTH HYPOTHESIS:}

'There is an evident relationship between the role of the state and the entrance of young men and women into employment in small businesses.'

Table 7: Display of the Arithmetic Mean and Standard Deviation of the sample of small business employees' responses to the questionnaire on the state's role and the entrance of young men and women into employment in small businesses

\begin{tabular}{|c|c|c|c|c|c|c|}
\hline & The Role of the State & $\begin{array}{l}\text { The } \\
\text { Mean }\end{array}$ & $\begin{array}{l}\text { Standard } \\
\text { deviation }\end{array}$ & Order & $\begin{array}{r}\text { Chi- } \\
\text { Square } \\
\text { Value }\end{array}$ & $\begin{array}{r}\text { Significanc } \\
\text { e level }\end{array}$ \\
\hline 1 & $\begin{array}{l}\text { Compelling owners of small businesses, } \\
\text { franchises and commercial agencies to employ } \\
\text { young Saudi people and offer them financial, } \\
\text { moral and social support. }\end{array}$ & $4 \cdot 30$ & 1.01 & 4 & $* *_{104.79}$ & Significant \\
\hline 2 & $\begin{array}{l}\text { Labor statistics, databases and available job } \\
\text { opportunities in the small business sector do not } \\
\text { exist. }\end{array}$ & 3.86 & 0.89 & 6 & $* * 21.20$ & Significant \\
\hline 3 & $\begin{array}{l}\text { Regulating shop opening working hours at eight } \\
\text { hours a day may contribute to encourage young } \\
\text { people to work in the private sector. }\end{array}$ & 4.32 & 0.84 & 3 & $* * 57.10$ & Significant \\
\hline 4 & $\begin{array}{l}\text { The quality of public education is not aligned } \\
\text { with the market needs and requirements of } \\
\text { small businesses. }\end{array}$ & 4.01 & 0.96 & 5 & $* * 52.67$ & Significant \\
\hline 5 & $\begin{array}{l}\text { Raising awareness, providing education and } \\
\text { encouragement of young men and women to } \\
\text { work in the handicrafts sector contribute in the } \\
\text { start-ups of private and small businesses. }\end{array}$ & 4.56 & 0.61 & 1 & $* * 96.35$ & Significant \\
\hline 6 & $\begin{array}{l}\text { The recovery of external remittances by migrant } \\
\text { workers and acting on their reinvestment in the } \\
\text { country contribute in the injection of hard } \\
\text { currency and enhancement of the Saudi } \\
\text { economy. }\end{array}$ & $4 \cdot 36$ & 0.93 & 2 & $* * 112.47$ & Significant \\
\hline & Weighted Average & 4.24 & 0.44 & & & \\
\hline
\end{tabular}

The indicators in Table (7) show the views of the sample of small business employees, participating in the current study, concerning the existence of statistical significance between the state's role and the entrance of young men and women into employment in small businesses. The table shows the Weighted Average of 4.24 for the responses of the survey sample and a standard deviation of 0.44 . Therefore, we conclude that the majority of the respondents in the sample agree to a great extent that the State plays a key role in the entrance of young men and women into employment in small businesses. We examine below the most prominent roles played by the State to encourage the entrance of young men and 
women into employment in small businesses. The results of Table (7) show that the state's most important role is in encouraging the entrance of young men and women into employment in the small business sector. This is represented in raising awareness, providing education and encouragement of young Saudis to work, for example, in the handicrafts sector, and contributes to the start-ups of private and small businesses. This result is supported by the arithmetic mean of 4.56 and a standard deviation of 0.61. Therefore, we conclude that the majority of the respondents in the sample agree that the State plays an important and crucial role in the process of raising awareness and encouragement of young people to work in the handicrafts sector, which drives them forward to start up their own private and small businesses. The results of Table (7) show that the recovery of external remittances by migrant workers and acting on their reinvestment in the country mutually contribute in the injection of hard currency and the enhancement of the Saudi economy. This element is considered the most prominent role of the state and has been awarded a very high rank of importance by the respondents. This result is supported by the arithmetic mean of 4.36 and a standard deviation of 0.93 . The results show that one of the state's roles in encouraging the entrance of young men and women into employment in the small business sector is represented in regulating shop opening working hours at eight hours a day in order to contribute to encourage young people to work in the private sector. This role has ranked the third and is supported by the arithmetic mean of 4.32 and a standard deviation of 0.84 . The results of Table (7) show that the majority of the respondents in the sample strongly agree that compelling owners of small businesses, franchise businesses and commercial agencies to employ young Saudis and offer them financial, moral and social support is considered one of the highest ranked roles of the state. This result is supported by the arithmetic mean of 4.30 and a standard deviation of 1.01. The results of Table (7) also indicates that both statements of the questionnaire represented in "the quality of public education is not aligned with the market needs and requirements of small businesses" and "labor statistics, databases and available job opportunities in the small business sector do not exist" have highly impacted the discouragement of young Saudis in employment in the small business sector. This result is supported by the arithmetic mean of (4.01 and 3.86) consecutively. The results of Table (7) also show that all Chi-Square values are statistically significant at the level (a) of 0.01 . This indicates that there is a statistically significant relationship between the state's role and the employment of young people in small businesses, a case which supports acceptance of the fifth study hypothesis. Therefore, from the analysis of the sample's views on the state's role in encouraging the entrance of young men and women into employment in small businesses we conclude that the most dominant and influencing roles are represented in raising awareness, providing education and encouragement of young people to work, for example, in the handicrafts sector. These efforts positively impact and contribute to increasing start-ups of private and small businesses; The recovery of external remittances by migrant workers and acting on their reinvestment in the country contribute to the injection of hard currency and enhancement of the Saudi economy; Regulating shop opening working hours at eight hours a day may contribute to encouraging young people to work in the private sector; Moreover, compelling owners of small businesses, franchises and commercial agencies to employ young Saudis and offering them financial, moral and social support is seen as a strong inducement for increased involvement of young Saudis in the private and small business sector of the KSA economy.

\subsection{THE RESULTS OF TESTING THE SIXTH HYPOTHESIS:}

'There are favorable and unfavorable factors which may either lead to young men and women being attracted by the idea of entering into employment in small businesses, or to them viewing such employment opportunities unfavorably and hence to their being reluctant to enter that employment sector.'

Table 8: Display of the Arithmetic Mean and Standard Deviation of the sample of small business employees' responses to the questionnaire on the existence of favorable and unfavorable factors which may either lead to young men and women being attracted by the idea of entering into employment in small businesses, or to them viewing such employment opportunities unfavorably and hence to their being reluctant to enter that employment sector. 


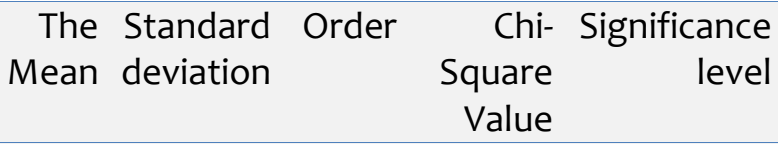

$1 \quad$ High unemployment rates have led many young women and men to enter into employment in small businesses or start up their own private$$
0.97
$$

1

$* * 64.59$

Significant business.

2 Many private business owners wish to educate their children to get a certificate in management, medicine or sciences instead of working in the family-owned business.

3 The continuous increase of the population and the high rate of those who fall into the youth category have led to a consumption-based economy and not a productive-based economy, and in the process the culture of saving is lost.

4 The low level of education of some businessmen led to their unwillingness to employ young people who hold university degrees.

5 Some small business owners tend to practice a sole administration of the business that eventually leads to the reluctance of kin and other young people from engaging in these businesses.

The Weighted Average

Significant

The indicators in Table (8) show the views of the sample of small business employees, participating in the current study, concerning the existence of favorable and unfavorable factors which may either lead to young men and women being attracted by the idea of entering into employment in small businesses, or to them viewing such employment opportunities unfavorably and hence to their being reluctant to enter that employment sector. The table shows the Weighted Average of 3.71 for the responses of the survey sample and a standard deviation of 0.57 . Therefore, we conclude that the majority of the respondents in the sample agree to a great extent that there are favorable and unfavorable factors which may either lead to the keenness or reluctance of young men and women to enter into employment in small businesses. We examine below the most prominent favorable and unfavorable factors which may either lead to the keenness or reluctance of young people to enter into employment in small businesses. The results of Table (8) show that one of the most important unfavorable factors that lead to the reluctance of young men and women to enter into employment in small business sector is represented in the statement that high unemployment rates have led many young women and men to enter into employment in small businesses or start up their own private businesses. This result is supported by the arithmetic mean of 4.07 and a standard deviation of 0.97. The following factor, in the second rank, is the statement that some small business owners tend to practice a sole and solitary administration of the business that eventually leads to the reluctance of kin and other young people from engaging in these businesses. This result is supported by the arithmetic mean of 3.97 and a standard deviation of 0.80 . The results in Table (8) indicate that the majority of the respondents in the sample believe that the wish of private business owners to educate their children to get a certificate in management, medicine or sciences instead of having them working in the family-owned business, is considered one of the unfavorable factors that leads to the reluctance of young men and women to enter into employment in small business sector. This result is supported by the arithmetic mean of 3.89 and a standard deviation of 0.91. The results in Table (8) also indicate that one of the factors that either lead to the keenness or reluctance of young Saudis to enter into employment in small businesses is represented in the continuous increase of the population and the high rate of those who fall into the youth category, which has led to the creation of a consumption-based as opposed to productive-based economy, during which process 
the culture of saving has been neglected or lost. Moreover, the low level of education of some businessmen led to their unwillingness to employ young people who hold university degrees. Therefore, we conclude from the indicators shown in Table (8) in respect to the favorable and unfavorable factors which may either lead to the keenness or reluctance of young people to enter into employment in small businesses, it is clear that the most significant favorable and unfavorable factors are represented in the following:

- High unemployment rates have led many young Saudis to enter into employment in small businesses or start up their own private business.

- Some small business owners tend to practice a sole and solitary administration of the business that eventually leads to the reluctance of kin and other young people to engage in these businesses.

- Many private business owners wish to educate their children to get a certificate in management, medicine or sciences instead of having them working in the family-owned business.

\subsection{THE RESULTS OF TESTING THE SEVENTH HYPOTHESIS:}

'There is a direct statistically significant correlation between the lack of job opportunities and social problems such as domestic discord and moral deterioration.'

Table 9: Display of the Arithmetic Mean and Standard Deviation of the sample of small business employees' responses on the existence of a direct correlation of statistical significance between the lack of job opportunities and social problems such as domestic discord and moral deterioration

\begin{tabular}{|c|c|c|c|c|c|c|}
\hline & & $\begin{array}{l}\text { The } \\
\text { Mean }\end{array}$ & $\begin{array}{l}\text { Standard } \\
\text { deviation }\end{array}$ & Order & $\begin{array}{l}\text { Chi- } \\
\text { Square } \\
\text { Value }\end{array}$ & $\begin{array}{r}\text { Significanc } \\
\text { e level }\end{array}$ \\
\hline 1 & $\begin{array}{l}\text { Lack of employment opportunities among } \\
\text { young women and men may lead to domestic } \\
\text { discord. }\end{array}$ & 3.51 & 1.16 & 3 & $* * 23.68$ & Significant \\
\hline 2 & $\begin{array}{l}\text { Lack of employment opportunities among } \\
\text { young women and men leads to a delayed age of } \\
\text { marriage for young people and contributes to } \\
\text { spinsterhood due to financial inability. }\end{array}$ & 4.59 & 0.82 & 1 & $* * 178.73$ & Significant \\
\hline 3 & $\begin{array}{l}\text { Lack of employment opportunities among } \\
\text { people can leads to moral deterioration and } \\
\text { even crime. }\end{array}$ & 4.24 & 0.94 & 2 & $* * 84.99$ & Significant \\
\hline & e Weighted Average & 4.11 & 0.69 & & & \\
\hline
\end{tabular}

The indicators in Table (9) show the views of the sample of small business employees, participating in the current study, concerning the direct correlation of statistical significance between the lack of job opportunities and social problems such as domestic discord and moral deterioration. The table shows the Weighted Average of 4.11 for the responses of the survey sample and a standard deviation of 0.69 . Therefore, we conclude that the majority of the respondents in the sample agree to a great extent that lack of job opportunities leads to many social problems such as domestic discord and moral deterioration. We examine below the analysis of the sample's views on the negative impacts of lack of job opportunities and their relation to social problems. The results in Table (9) show that one of the most important negative impacts of lack of job opportunities is represented in the statement "lack of employment opportunities among young women and men leads to a delayed age of marriage for young people and contributes to spinsterhood due to financial inability." This result is supported by the arithmetic mean of 4.59 and a standard deviation of 0.82 . Therefore, we conclude that there is a very high impact for lack of job opportunities among young men and women. The most significant negative impact is the delayed age of marriage for young people, a case which contributes to increasing spinsterhood levels - already 
characterized as being alarmingly high. Consequently, lack of job opportunities for young people contributes to increased spinsterhood levels. The results in Table (9) also show that one of the negative impacts of lack of employment opportunities among young people is leading to moral deterioration and even to crime. The respondents in the sample agreed to a great extent that crime levels, wrongful conduct and moral deterioration, in consequence, is likely to increase due to lack of employment opportunities among young people. This result is supported by the arithmetic mean of 4.24 and a standard deviation of 0.94 . The results in Table (9) also show that the majority of the respondents in the sample agree that lack of employment opportunities among young women and men may lead to domestic discord and even domestic violence. This result is supported by the arithmetic mean of 3.51 and a standard deviation of 1.16. The results of the Table also show that all Chi-Square values are statistically significant at the level $(\alpha)$ of 0.01 . This indicates that there is direct correlation of statistical significance between the lack of job opportunities among young Saudis and social problems such as domestic discord and moral deterioration. Therefore, lack of employment opportunities for young Saudis is considered one of the key factors for the emergence and prevalence of troubling social phenomena that can, if not addressed, have serious societal consequences.

\subsection{CONCLUSIONS}

1. The Study shows that work environment plays a main role in the unwillingness of young Saudis to enter into employment in small business sector. The results of the study show that the most important element of the work environment facing young people is the non-application of civil service standards such as retirement and promotion systems, employment laws and job stability. The second ranked obstacle is the size of the small businesses sector and their inability to offer salary payments to young Saudis commensurate with the salary and compensation schemes of public/government sector employees - which leads them to prefer to wait and seek employment opportunities in the public/government sector or in enterprises in other sectors characterized by job security and stability.

2. The study shows that society's views and perceptions of some businesses and low-skilled jobs have a high impact on the discouragement of young people's employment in small businesses or the startup of their own small private business - which have proven to provide a higher income than other jobs.

3. The study proves the existence of a relationship between young people's strong ambitions and the non-utilization of job opportunities in the small business sector. The study also shows that the most important indicator to young people's ambitions is represented in the statement that some lowskilled jobs such as plumbing, electrical wiring and construction jobs do not in any way align with the aspirations of young people. In addition, there are there are some jobs that are considered as undesirable or unpleasant by young Saudis such as working in fast food restaurants and small industrial workshops.

4. The study shows that businessmen's perspectives of young Saudis have strongly influenced the nonappointment of young Saudis in available job opportunities in the small business sector. A case that has entailed the foreign workers' acquisition of a disproportionally larger share of jobs in the private sector, particularly in the small business sector, which represents a high percentage of the volume of business in KSA.

5. The study shows that the state plays an important role in encouraging the entrance of young men and women into employment in the small business sector. The study shows that the most dominant and influencing roles are represented in raising awareness, providing education and encouragement of young people to work, for example, in the handicrafts sector and that these efforts contribute to start-ups of private and small businesses; The recovery of external remittances by migrant workers and acting on their reinvestment in the country contribute to the injection of hard currency and enhancement of the Saudi economy; Regulating shop opening working hours at eight hours a day may contribute to encourage young people to work in the private sector; Moreover, compelling owners of small businesses, franchises and commercial agencies to employ young Saudis and offering them financial, moral and social support is seen as a strong inducement for increased involvement of young Saudis in the private and small business sector of the KSA economy. 
6. The study shows the most important favorable and unfavorable factors which may either lead to young men and women being attracted by the idea of entering into employment in small businesses, or to them viewing such employment opportunities unfavorably and hence to their being reluctant to enter that employment sector. It is clear that the most significant favorable and unfavorable factors are represented in the following: High unemployment rates have led many young women and men to enter into employment in small businesses or start up their own private business; Some small business owners tend to practice a sole and solitary administration of the business that eventually leads to the reluctance of kin and other young people to engage in these businesses; Moreover, many private business owners wish to educate their children to get a certificate in management, medicine or sciences instead of working in the family-owned business.

7. The study shows that there is a direct correlation between the lack of job opportunities for young Saudis and social problems such as domestic discord/violence and moral deterioration and even suicide. Therefore, lack of employment opportunities for young Saudis is considered one of the key factors for the emergence and spread of troubling social phenomena which might, if not addressed, result in serious social concerns.

8. The study shows the importance of providing bankruptcy insurance coverage to protect these businesses against risks. This action encourages young people to enter into employment in these businesses, since a lot of young people do not start up such businesses for fear of losing their capital.

\subsection{RECOMMENDATIONS}

1. Provide adequate work conditions for young people to engage in work in small businesses such as working hours, work premises, and the application of work systems similar to the civil service system including salary schemes, wages, job stability, and retirement programs.

2. Set up of a Small Business Committee formed of businessmen from the private sector including large, small and medium sized enterprises, commercial banks, government authorities from the Ministry of Industry and Trade, Ministry of Information, and members from the municipal council, educational and professional boards. One of the Committee's duties should be to create a database for all young candidates requiring job opportunities, as well as to monitor the reports furnished by these businesses.

3. Provide special attention to young Saudis since they are considered the nations' vital human resource and its pillars of development. Awareness and correct perceptions should be raised and nurtured in young people, in addition to taking action to encourage them to enter into employment in small businesses such as through loan provision, management and accounting consultation. The concept, common among young people, that low-skilled jobs are somehow socially demeaning should be completely eradicated. Efforts should be made to promote the culture, values and principles of hard work among young people, in addition to raising their spirits, boosting their morale and equipping them with the confidence that employment is not limited to public sector/government jobs but that there are also broader opportunities in small businesses. (Al-Ghamri, 2009)

4. Provide insurance coverage to protect small businesses against failure risks and design a tailored mechanism for the sector to alleviate anxiety of small business start-ups. (World Bank Group, 2012)

5. Establish Joint Stock Companies in the fields of maintenance of buildings, construction and car maintenance where young people are employed and become shareholders by stock purchase. Such companies can be placed under the supervision of official authorities during establishment periods and for the following five years.

6. Set up corporate governance guidelines for small businesses and family-managed businesses to ensure continuity.

7. Encourage young people to buy franchises and enter into commercial agency agreements with wellknown established commercial brand names that wish to enter the Saudi market. Facilitate the registration procedures and assist in securing permits and licenses which will, in turn, contribute to facilitating the bank loan process for many young people. Since franchise companies have previous experience in commerce and business and many are known to commercial banks, credit decisions can be accelerated due to guarantee of secured repayment of the loan amount. (Al-Ghamri, 2009) 
8. Implement a revised version of curriculum and pay special attention to Vocational Training Institutes. Examine the learning outcomes with the goal of aligning the educational system with labor market needs. (Al-Otaiby, 2011)

9. Take advantage of other countries' experiences and successes in facing the problems of young people. (Al-Sous, 2010)

10. Restrict foreigners from competing with young Saudis in many professions such as restaurants, grocery stores, construction and car maintenance. Take action to replace migrant workers with young Saudis gradually and prevent issuance of visas. (Al-jabr, 2014)

11. Oblige companies to provide job opportunities for young Saudis.

12. The community should seriously consider the provision of career opportunities for young people. Lack of cooperation between involved entities can result in several other problems such as moral degeneration, and crime. Our dependency on foreign workers should be reduced and from early childhood the emerging generation should absorb the best from the example or qualities of foreign culture and traditions and develop their own strong innovative and entrepreneurial spirit. (Al-Azraki, 2015)

13. Attention must be given to this subject by means of research and scientific studies aimed at the identification of appropriate strategies and solutions to effectively reduce and address its consequences in future.

14. At this crucial historical juncture, with the widely recognized need for economic diversification, there is surely no better time to address the issue of encouraging and fostering the vital human resource of the Saudi youth and facilitating their effective and successful entry into gainful private sector/small business employment and start-ups.

\section{REFERENCES}

Al-Asraj, H. A. M., (2010). Small and Medium-Sized Enterprises and Their Role in Provision of Workforce in the Arab Countries. Cairo, Egypt.

Al-Azraqi, S., (2015). Unemployment Fuels Crime and Violence. Al-Sabah Al-Jadeed Newspaper. Vol. 6715. Cairo, Egypt. Accessed $14^{\text {th }}$ of March, 2016. $\quad$ http://www.newsabah.com/wp/newspaper/39889

Al-Ghamri, N. S., (2009). The Role of Franchising in the Success and Failure of Small Enterprises: An Exploratory Study in the Province of Jeddah. Department of Business Administration, Faculty of Economics and Administration, King Abdulaziz University, Jeddah, Saudi Arabia

Al-Jabr, I., (2014). Real Saudization Could Start With the Grocery Store. Al-Sharq Newspaper. Issue No. 894. Accessed $14^{\text {th }}$ of March, 2016. http://www.alsharq.net.sa/2014/05/16/1143402

Al-Jundi, A.B., (2015). Small and Medium-Sized Businesses Account for $90 \%$ of the Economy of Any Country. Al-Akhbar Newspaper, Cairo, Egypt.

Al-Otaibi, T., (2011). The Shura Council's Efforts to Confront the Issue of Unemployment. Naif Arab University for Security Sciences, Riyadh, Saudi Arabia.

Al-Saidani, Al-Mongi (2010). The Fourth Suicide Case Due to Unemployment. Middle East Magazine, No. 11717, December $15^{\text {th }}$ London, UK.

Al-Sous, S.Z., (2010), Some Successful International Projects in the Field of Development of Small and Medium-Sized Enterprises. The Ministry of National Economy, Palestine.

Arab Labor Organization (2009). The Role of Small and Medium-Sized Enterprises in Easing Unemployment Crisis. Workshop Paper presented at the Arab Employment Forum, Bierut, Lebanon.

Baybars, S., (2015). Experts Call for Diversifying the Sources of Financing Small and Medium-Sized Enterprises. Al-Ghad Online Newspaper. Amman, Jordan. Accessed $15^{\text {th }}$ March 2015 http://www.alghad.com/articles/883511.

Dawabbah, A., (2006). The Problematic Issues in Financing Small and Medium-Sized Enterprises in the Arab Countries. Administrative Research Journal, $4^{\text {th }}$ Edition, October, $10^{\text {th }}$. Centre for Counseling, Research and Development, Cairo, Egypt.

Ernst and Young (2013). Avoiding a Lost Generation: Young Entrepreneurs Identify 5 Imperatives for Action. Paper presented for the G20 Young Entrepreneurs' Alliance Summit, Moscow, Russia. 
Lazem, Y., (2014). A Small Business Idea that Turned Owner into a Millionaire. Al-Nahar Magazine. Accessed $15^{\text {th }}$ of March, 2016. https://www.zawya.com/ar/story/ZAWYA20140120062523

Mefleh, S., (2016). Personal Interviews - A Modern Concept for Securing a Job. Administrative Development Magazine Issue No. 132, p. 35.

Miqdad, M., and Bahloul, M., (2012). Unemployment of Graduates of the School of Business and The Role of Small Businesses in Combating It. Workshop Paper Presented at the "Youth and Development In Palestine: Issues and Solutions". Gaza, Palestine

Obeidat, T.,, Adas, A., and Abdulhaq K., (2016). Scientific research, Its Concept, Tools and Approaches. AlFikr Publications and Distributions. Amman, Jordan.

Riyadh Chamber of Commerce \& Industry (RCCI) (2010). Towards Identifying Problems and Challenges Facing Young Entrepreneurs in the Saudi Economy. A Workshop Paper. Riyadh, KSA

Saif, R., (2013). Small Enterprises and Its Contribution in Reducing Povery and Unemployment in Society. Arabian Gulf Workers' News Agency. Amman, Jordan.

Salibi, J. S., (2012). Small and Medium-Sized Industrial Enterprises - Reality and Prospects Directorate of Industrial Statistics. Page 3.

Schoof U (2006). Stimulating Youth Entrepreneurship: Barriers and Incentives to Enterprise Start-ups by Young People. SEED working paper No. 76. Series on Youth and Entrepreneurship. International Labour Organization. Geneva, Switzerland.

Trade and Development Board and the Investment Committee for Engagement and Development (2014). United Nations Conference on Trade and Development Conference Geneva, Switzeralnd.

World Bank Group (WBG) (2012). Multilateral Investment Guarantee Agency. Ensuring Opportunities. Washington, United States. 